\title{
L ARCA DE LAS INSACULACIONES: UNA OBRA MALLORQUINA DE JOAN OMS
}

\author{
CONCEPCIÓ BAUÇÀ DE MIRABÒ GRALLA
}

Centro de Enseñanza Superior Alberta Giménez cbauca@cesag.org

Resumen: El arca de las insaculaciones es un bien mueble del patrimonio español que aúna el valor histórico y el artístico. Su funcionalidad ligada a la elección de cargos de las antiguas instituciones de la isla de Mallorca o régimen de insaculación, se enriqueció gracias a su concepción escultórica, a su discurso manierista y a una tipología formal de la que no conocemos paralelos. Una investigación documental ha revelado el contrato de fabricación y en consecuencia, la fecha y autoría. Se trata de una obra realizada en 1669 por Joan Oms, escultor perteneciente a una conocida saga mallorquina. La información, inédita hasta ahora, confirma y amplía además la relación del arca existente con las obras llevadas a cabo en el edificio de la Casa de la Universidad, actual Ayuntamiento de Palma, en el siglo XVII.

Palabras clave: Patrimonio / escultura / mobiliario / insaculaciones / Oms.

\section{THE ARK OF THE INSACULATIONS: A MAJORCAN WORK BY JOAN OMS}

Abstract: The Ark of the Insaculations is a movable asset of the Spanish heritage that combines historical and artistic value. Its functionality linked to the election of positions in the old institutions of the island of Majorca or the insaculation regime, was enriched thanks to its sculptural conception, its mannerist discourse and a formal typology of which we do not know parallels. A desk investigation has revealed the manufacturing contract and, consequently, the date and authorship. It is a work made in 1669 by Joan Oms, a sculptor belonging to a well-known Mallorcan saga. The information, unpublished until now, also confirms and expands the relationship of the existing ark with the works carried out in the building of the University House, current Palma City Council, in the seventeenth century.

Key words: Heritage / sculpture / mobiliary / insaculations / Oms.

\section{Introducció}

L'arca de les insaculacions que actualment es custodia a l'Ajuntament de Palma, ubicat a la plaça de Cort, és un bé singular del patrimoni historicoartístic de les Illes Balears pel seu significat simbòlic, per la seva vàlua artística i per la seva origina- litat. El present estudi es fa amb motiu de la seva restauració encarregada per l'Ajuntament. ${ }^{1}$

La consideració de l'arca de fusta com a un moble freqüent en l'àmbit espanyol durant l'Edat Moderna, contribueix a revalorar l'obra que ens ocupa com un exemplar únic. ${ }^{2}$ Està estructurada en dos

\footnotetext{
* Fecha de recepción: 15 de abril de 2020 / Fecha de aceptación: 13 de julio de 2020.

1 En aquest context, vull agrair als membres de Xicaranda. Conservació i restauració de béns culturals, S. L. la seva disponibilitat i molt especialment a la catedràtica Catalina Cantarellas el seu ajut en la present investigació.

2 La denominació d'arca respon a la que tradicionalment ha rebut el moble i està d'acord amb la seva importància, que supera la d'una caixa. En aquest sentit respon a la definició del mot "arca" que l'Academia Española de la Lengua repetí entre
} 


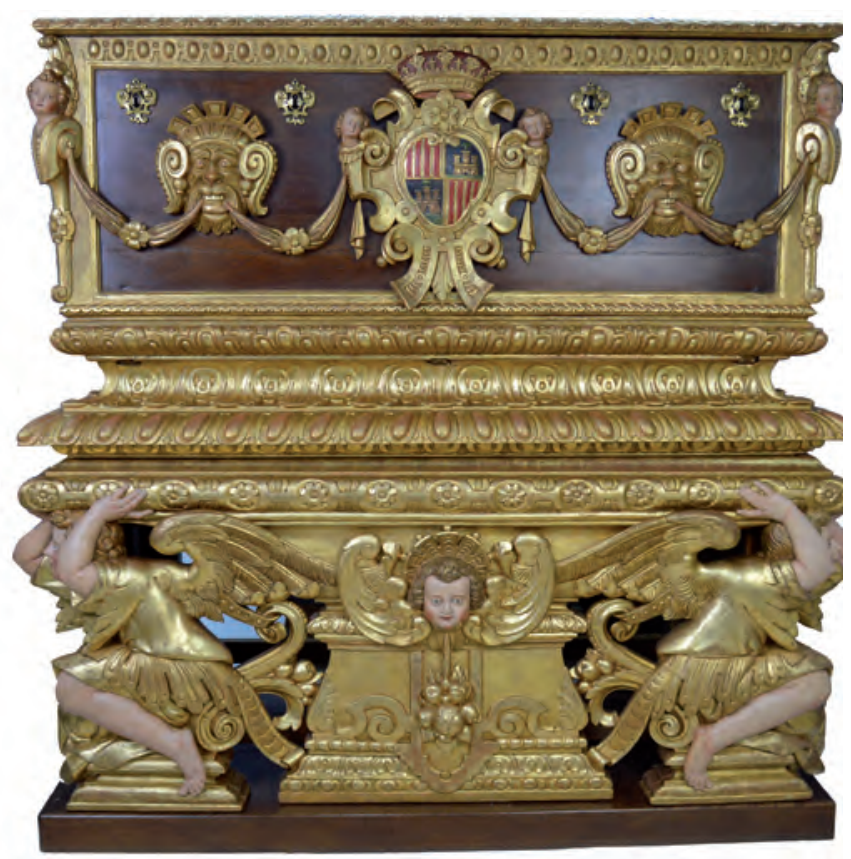

Fig. 1. Arca de les insaculacions de Cort.

cossos. Les seves dimensions (163 x $173 \times 69 \mathrm{~cm})$, la talla i el daurat que presenta contribueixen a dotarla d'una importància inusual. El cos inferior compta amb tres cares tallades, mentre la quarta permet veure l'estructura que suporta tota la peça. La frontal està protagonitzada per una peanya trapezoïdal decorada amb fulles d'acant, motius auriculars i motllures que culminen en un cap alat de querubí del qual penja un pom de fruites. El flanquegen dos suports antropomorfs en forma d'àngels-atlants agenollats. Sustenten una desenvolupada base sobre la que recau el cos superior, rematada amb motllures. Les cares laterals repeteixen el motiu de la peanya culminada pel cap d'àngel, flanquejada per volutes i elements vegetals. Tot el cos inferior està acabat combinant daurats i policromia.

El cos superior s'introdueix des de la base motllurada decorada amb cercles inscrits, oves, gallons i motius vegetals sobre les quals s'assenta la caixa rectangular. Aquesta és de fusta envernissada so- bre la que destaquen relleus daurats i policromats. El frontal principal, abatible, té forma de plafó limitat per motllures i es tanca amb quatre panys de metall cisellat. A l'interior aquests es corresponen amb quatre grans escuts de ferro, com també ho són les frontisses que permeten l'obertura. Aquests elements resulten bàsics pel funcionament del moble i tingueren un gran protagonisme, donat que a cada pany hi correspon una clau que es conserva i que era guardada per una persona distinta. $^{3}$

El més important dels relleus decoratius del cos superior és el blasó de la Universitat i Regne de Mallorca, situat al centre i format per cartrons retallats, decorat amb querubins en forma d'estípit i culminat per una corona. El flanquegen dues màscares monstruoses $\mathrm{i}$ altres dos àngels-estípits en les cantoneres. Tots ells s'uneixen entre si per draps en forma de garlanda. Els frontals laterals mostren els plafons buits i només es decoren amb les motllures que recorren el perímetre, igual que la tapa superior.

Des de la seva fabricació, el moble protagonitzava cada any cinc sessions del Consell de la Ciutat de Mallorca, regit pel règim d'insaculacions instaurat per Alfons el Magnànim el 1447 a l'illa. ${ }^{4}$ La insaculació, coneguda com el Regiment de sort e de sach, era el sistema mitjançant el qual s'elegien els càrrecs més representatius de l'administració pública. Es servia d'una arca tancada amb quatre panys que es trobava a la Casa de la Universitat, seu de la institució corresponent al govern municipal i que servia també com a seu del Gran i General Consell. A dins allotjava una segona caixa tancada amb tres panys que es transportava a la Sala del Consell. ${ }^{5}$ Aquesta guardava un sac destinat a cada estament (cavallers, ciutadans, militars, mercaders i menestrals), de cada un dels quals un infant extreia a sorts els rodolins de cera que contenien els noms dels jurats i consellers que havien de representar els ciutadans. ${ }^{6}$

Des del segle XV l'esmentat sistema d'elecció s'estengué àmpliament per tota la Corona d'Aragó, on existien caixes amb la mateixa funció que s'anirien

1726 i 2001: "Caja grande con tapa llana, afirmada con goznes para poderla abrir y cerrar, para cuya seguridad tiene su cerradura. Sirve regularmente para guardar lo que es de estimación y también las cosas que son manuales". Transcrit per RODRíGUEZ LÓPEZ, María del Carmen, 2014, p. 198.

${ }^{3}$ En aquest sentit el moble es pot comparar amb altres tipologies més freqüents com les arques de cabals o les de documents. Vegeu al respecte: AGUILÓ, María Paz, 1993, p. 171-216; RODRÍGUEZ LÓPEZ, María del Carmen, 2014, p. 193-197.

${ }^{4}$ VIDAL, Josep Juan, 1998, p. 10.

${ }^{5}$ La mobilitat de la caixa que contenia els redolins amb els noms dels insaculats es repeteix en altres peces homònimes, com per exemple la de Terol. LATORRE CIRIA, José Manuel; PÉREZ PÉREZ, Isabel, 2006, p. 62-63.

${ }^{6}$ VIDAL, Josep Juan, 1998, pp. 13-14. Vegeu també FURIÓ, Antoni, 1966, p. 56. 
renovant durant l'Edat Moderna. Solien conservarse als arxius dels consistoris. ${ }^{7}$ Avui es coneixen les normatives que incloïen l'ús d'arques en distintes ciutats i ha arribat fins l'actualitat alguna d'aquelles peces, com per exemple la d'Osca, fabricada el 1668, o la de Tudela, fora de la Corona d'Aragó. La que ens ocupa és la darrera que s'utilitzà a Palma, reemplaçant una altra gòtica que no s'ha conservat.

El règim de la insaculació finalitzà arran del Decret de Nova Planta, que comportà la suspensió de les antigues institucions privatives del Regne de MaIlorca a principi del segle XVIII. En conseqüència, I'arca es convertí en un moble secundari, desposseïda del seu sentit i del seu ús primigeni. Seria ja en època contemporània quan assolí la condició de bé patrimonial i a poc a poc es despertà l'interès per la seva datació, autoria i conservació.

\section{Estat de la qüestió}

En general es pot afirmar que la historiografia del moble no s'ha fixat en l'arca de les insaculacions, malgrat dins l'àmbit espanyol s'hagin vingut destacant peces mallorquines dels segles XVII i XVIII. Tampoc ha estat difosa en l'àmbit balear fins a temps recents.

Les cròniques sobre la història de Mallorca recullen tot allò referent a l'estructura del govern municipal, sense detenir-se en el moble que el possibilità. Al segle XIX, en el context del Romanticisme, es reivindicà l'Edat Mitjana i en particular I'antic Regne de Mallorca. Conseqüentment, es va atendre a l'edifici de I'antiga Universitat, del qual se'n destacà la volada, i ja a final de segle la façana barroca.

Pel que fa a l'interior, a les acaballes del segle XVIII les mencions escassegen ${ }^{8}$ i només augmenten -amb una sèrie d'excepcions- en la centúria següent, quan es centren tanmateix en les pintures, sobretot en la sèrie de retrats dels Fills II.lustres. Així per exemple la magna obra de Pascual Madoz, en parlar dels edificis del centre de Palma, ressenya l'existència de quatre-cents tres quadres i sols detalla el Sant Sebastià de Van Dyck. ${ }^{9}$ José María Quadrado, director de l'Arxiu del Regne -que llavors es trobava emplaçat a l'entresol de la Casa Consistorialltampoc esmenta la caixa en ampliar l'obra de Pau Piferrer el 1888. ${ }^{10}$

D'igual forma, la peça no meresqué l'atenció de Bartomeu Ferrà i Perelló al seu Álbum artístico de Mallorca, on, a més de donar escassa visibilitat a l'art de l'època moderna, optà per incorporar peces de propietat particular. ${ }^{11}$ Entre elles només es comptabilitzaren cinc arques i arquilles, ben distintes a la de Cort.

Probablement s'ha d'afegir a l'escàs interès que despertà el moble en el context decimonònic, la seva ubicació. Llavors es trobava al "saló d'hivern", una sala petita que devia restar fora de la vista del públic. Finalment i per tancar les aportacions del Vuit-cents, val a dir que el 1894 es reconegué la seva importància quan s'ordenà la seva restauració després de l'incendi de l'edifici de l'Ajuntament. ${ }^{12}$

Durant el segle XX I'obra ha merescut major atenció, però no ha estat objecte d'estudis monogràfics. Les guies de Palma seguiren la tònica anterior, ${ }^{13} \mathrm{i}$ no fou fins els anys seixanta que es donà un creixent interès pel tema. Aquest es concretà en cercar possibles atribucions, malgrat fossin formulades en clau d'hipòtesi a partir dels seus trets estilístics. Així I'historiador Joan Muntaner Bujosa relacionà l'arca amb algun dels escultors que en el darrer quart del segle XVII treballaven a les obres de la Casa de la Ciutat, donades les semblances que mostrava respecte a l'edifici. ${ }^{14}$

Als anys setanta $\mathrm{i}$ ja des de la mirada especialitzada de I'historiador de l'art, Santiago Sebastián emmarcà l'obra en el context de la influència manierista, referint-se als atlants amb ales del cos in-

\footnotetext{
7 GARCÍA RUIPÉREZ, Mariano, 1999, p. 132.

8 VARGAS PONCE, José, 1787.

9 MADOZ, Pascual, 1845-1850, vol. 13, p. 584; MEDEL, Ramón, 1849; HABSBURGO LORENA, Archiduque Luis Salvador, 2003, p. 302-303.

10 Lògicament Piferrer d'acord amb el seu ideari l'omet. PIFERRER, Pablo; PARCERISA, Xavier, 1842. Tampoc Quadrado en I'ampliació a l'obra del català, l'esmenta i es limita a citar l'arxiu: PIFERRER, Pablo; QUADRADO, José Maria, 1968, p. 252.

11 L'Àlbum de Ferrà es pot consultar online, tant l'únic publicat FERRÁ, Bartolomé; VIRENQUE, Julio, 1873, com la sèrie que restà inèdita: BASSEGODA I HUGAS, Bonaventura, 2017. Quant a les tipologies més usuals ell mateix descriu: "Ses caxes ordinaries y més vistes per tot, que eran de nogué amb frisos de relleu, y cariátides ó figures dretes à ses cantonades". FERRÁ PERELLÓ, Bartolomé, 1970, p. 1.

12 PONS I FÁBREGAS, Benito, 1895, p. 138.

13 Són els casos de VERRIÉ, Fréderic Pau, 1948, p. 83, i de MATHEU MULET, Pedro Antonio, 1958, p. 143-144.

14 MUNTANER BUJOSA, Juan, 1968, p. 14-15.
} 


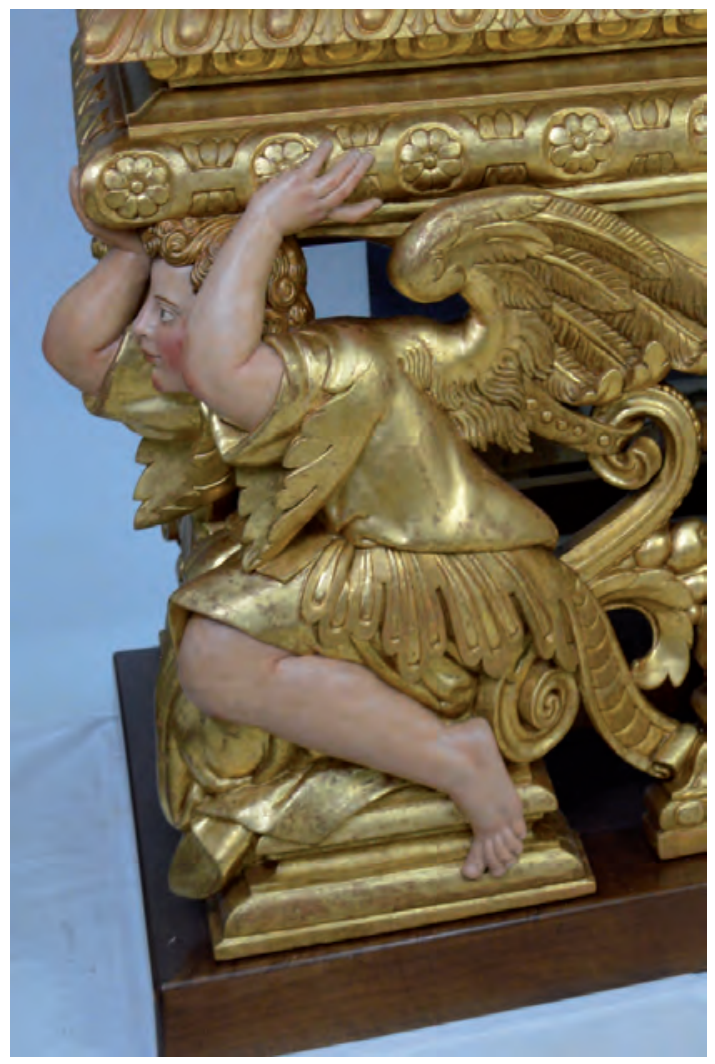

Fig. 2. Detall d'un àngel-atlant del cos inferior.

ferior i la connectà amb l'estil de l'escultor Gabriel Torres, autor de la volada de Cort. ${ }^{15}$ En la dècada dels noranta Mercè Gambús insistí en el tractament manierista de la peça. ${ }^{16}$

Amb posterioritat, Marià Carbonell, malgrat que en un primer moment recollí l'atribució feta per Sebastián, adoptà una nova postura en detallar que l'arca conservava alguns elements pròxims a I'estil de Joan Antoni Oms i Antoni Carbonell, els altres dos escultors que havien treballat a la façana de Cort. A més, defensà els àngels-atlants i els àngels-estípits com a característics del taller dels Oms. ${ }^{17}$ D'altra banda i en un estudi dedicat al re- taule mallorquí protagonitzat per les figures amb atlants, Andreu Josep Villalonga defensà la generalització d'aquesta tipologia concreta a partir del taller de Joan Antoni Oms. ${ }^{18}$ Des d'ell s'hauria tramesa a un dels seus fills Gaspar i a altres artistes durant la segona meitat del segle XVII. Tanmateix atribuí la caixa al mencionat Joan Antoni, opinió que s'ha reiterat després. ${ }^{19}$

En aquest punt cal fer notar que els autors precedents tractaren l'arca de les insaculacions com un objecte escultòric, relacionant-la amb alguns dels artistes mallorquins coneguts. Però la peça s'ha ressaltat també des del camp d'estudi del mobiliari, que comptà amb grans artesans a l'illa durant el Barroc. Al respecte cal citar a Jaume Llabrés, que malgrat recollí les atribucions fetes per Sebastián y Carbonell, proposà també l'existència d'un possible "cercle de la Sala". Aquest vinculava la caixa també amb un retaule -el de Santa Teresa de Jesús del convent concepcionista de Sineu- $\mathrm{i}$ amb alguns mobles mallorquins destacats com el llit de Can Granada, ${ }^{20}$ amb el capçal tallat amb formes manieristes, tot daurat. Finalment i des del punt de vista de la història del mobiliari illenc Kika Coll considerà la peça com un exemplar únic. ${ }^{21}$

\section{La comanda de l'arca a mestre Joan Oms}

Partint del coneixement existent $\mathrm{i}$ aprofitant l'avinentesa de la restauració de l'arca ens plantejàrem la necessitat d'engegar una recerca arxivística, en la convicció de que una obra de tal envergadura i rellevància simbòlica no podia haver passat desapercebuda al registre dels comptes de l'època. Amb tot, la pèrdua de gran part de la documentació lligada a la casa consistorial degut a l'incendi que patí en 1894 i la consulta prèvia dels especialistes auguraven pocs resultats.

Iniciàrem la investigació a partir de l'inici de la profunda reforma duta a terme en la casa dels jurats. El finançament de les obres anava a càrrec del pressupost destinat a la Fortificació del Regne i comptava amb la col.laboració de la Universitat. ${ }^{22}$ Avui la documentació relacionada es conserva parcialment

\footnotetext{
15 SEBASTIÁN LÓPEZ, Santiago; ALONSO FERNÁNDEZ, Antonio, 1973, p. 58; SEBASTIÁN LÓPEZ, Santiago, 1974, p. 251-252.

16 GAMBÚS SAIZ, Mercè, 1991, p. 201.

17 CARBONELL I BUADES, Marià, 1996, vol 4, p. 318-320; 2002, p. 31, 111.

18 "Con el tiempo Oms convertiría los soportes antropomorfos en una de las señas de identidad más características de su arte, las estípites principalmente $y$, al final de su carrera, los atlantes". VILLALONGA VIDAL, Andreu Josep, 2006, vol. 1, p. 517-518.

19 POU AMENGUAL, Miquel, 2014, p. 177.

20 LLABRÉS MULET, Jaume, 2009, p. 15.

21 COLL, Kika, 2009, 142, 144.

22 GAMBÚS SAIZ, Mercè, 1998, p. 94-96.
} 
a l'Arxiu del Regne de Mallorca, ja que les actes periòdiques corresponents a dita època es cremaren en la major part. ${ }^{23}$ Malgrat tot, I'arxiu conserva una sèrie documental anomenada "Extraordinaris d'Universitat" que reuneix les juntes realitzades pels jurats a fi de tractar temes especialment rellevants. Sens dubte l'arca de les insaculacions ho fou, per la seva importància i per l'elevat cost que degué suposar la seva fabricació.

Les actes de mitjan segle XVII recullen assumptes puntuals lligats a la defensa de l'illa, problemes veïnals, drets, concessions o establiment de preus. Quant als temes que afectaven directament la Casa de la Universitat enregistren regularment el nomenament de càrrecs municipals, l'extracció de doblers de l'anomenada "caixa gran", on es servaven els recursos econòmics de la taula de la institució i les despeses efectuades en els distints edificis lligats a aquesta.

El 1650 una profunda renovació de la casa dels jurats s'inicià amb la nova façana decorada per l'escultor Joan Antoni Oms al primer cos. Les obres es desenvoluparen lentament, fins que el 1665 una ordre reial disposà pagar mil lliures anuals, a compte de la Fortificació. ${ }^{24}$ Poc després la fàbrica de l'edifici continuava al pis noble, amb Antoni Carbonell com a escultor substituint a Oms, que havia mort. El 16 juliol de 1667 l'acta dels jurats recollí el manament que rebaixava la quantitat destinada a la casa:

Que el gasto de las obras de picapedrer, fuster y pertrets que sens limitació se ha acustumat fer fins al present en las casas universals com són Studi General, la Crianssa, Miñonas, Rebhas, la Pietat, la Quartera, Banch del oli, Vitigal, Pes del carbó, de la palla, de formatge, de la datina, y sèquias mestres et alias, salvo la Casa y Sala de la Universitat per el reparo de la qual jas troben destinadas mil lliuras, de aquí al devant sia solament de siscentas lliuras, compresas las doscentas lliuras del sobredit capítol y que estas degué girar el clavari a los magnífichs jurats per semanas qui aniran reparant y gastant en ditas casas y llochs, sens ques pugui gastar major summa de las ditas 600 L, ni restar en dèbit per la nova juraria, per a cade qual de las jurarias ha de star limitada al dit gasto de siscentas lliuras, ni ha de restar en dèbit per la nova juraria per las ditas obras y pertret sots la dita pena de haver ho de pagar de sos diners propis, no emperò de la Universitat ni de las $600 \mathrm{~L}$ que se hauran de gastar lo saguent añy. ${ }^{25}$

Enmig d'un clima generalitzat d'estalvi en totes les obres que depenien de la Universitat, es reduïren a sis-centes les mil lliures dedicades pel fons de la Fortificació a la reforma de la casa dels jurats. A més cal afegir que, en principi, la decoració interior de l'immoble no es podia pagar de dit fons. Si bé alguns anys abans la institució comptava amb cent lliures anuals per aquestes tasques, ${ }^{26}$ sembla que ara tenia menys diners. Però un pic avançades les obres, I'habilitació dels interiors resultava indispensable. En aquell context es documenten "I'entoldat del saló de la governació" i la compra de quatre cortinatges que costaren deu lliures el 1667. ${ }^{27}$ Sens dubte, la següent notícia enregistrada al respecte resulta cabdal, ja que es refereix al mal estat de l'antiga arca, gòtica:

Die $\mathrm{V}$ mensis januarii anno a nativitate domini MDCLXVIIII (1669).

Sobre los tàlechs de insaculació de oficis reals y universals.

Convocats, congregats y ajuntats su señoria dels illustres y molt magnífics senyors don Antoni Dameto donsell, Nicolau Andreu Rossiñol de Defla, Francesc Armengol ciutadans, Joan Gibert y Gabriel Rius mercaders y Joan Rabassa argenter, jurats lo corrent any de la Universitat, Ciutat y Regne de Mallorca, en la sala inferior juntament ab lo magnífic doctor Joseph Bassa advocat perpetuo de la Universitat, fonch proposat per lo illustre senyor don Antoni Damento que bé sabia su señoria que la arca ahont se troben tots los sachs de insiculations dels officis reals y universals no es troben en la decència diguda, com lo regonegué su illustríssima del senyor virrey en la última extracció en que vingué a presidir en ella, y axí que convé posarle en major forma, en part y aposento particular (tatxat) ahont se tengue solament esta, ana fabricant nous talechs y tapit per cobribufet al uso.

Y com per estos gastos se offerescan circa trescentes Iliures poch més o manco, y essent esta obra tan necessària, si de les mil lliures que se magestad ab se real carta de 20 agost 1665 té permès al Regne pugue su señoria dels magnífics jurats gastar en obres de la Casa de la Universitat, si es faran ditas obras de arca, aposento y bossas, cobri bufet, y demés que convenga, y si se farà destos diners.

Y havent oyt el parer del dit doctor Joseph Bassa de / degué el fer dits gastos de dit compte no se opose a la real orde, ans bé és conforme al tenor de ella, risol-

\footnotetext{
${ }^{23}$ Els llibres d'obra conservats a l'Arxiu del Regne de Mallorca (ARM) només arriben fins a 1650.

24 GAMBÚS SAIZ, Mercè, 1998, p. 99.

${ }^{25}$ ARM, AH EU 78, Extraordinaris Universitat 1667-1670, fol. 12v.

26 "Més per lo adorno de las cases de la Universitat se pot arbitrar un añy ab altre cent lliures... 100 L". ARM, AH EU 73, Extraordinaris Universitat 1654-1656, fol. 158v.

27 ARM, AH EU 78, Extraordinaris Universitat 1667-1670, fol. 16r, 16v.
} 
gueren de fer dita obra y pagarla del dit compte, atteses las rahons sobreditas.

De tot lo qual para que const ad eternam rei memoriam se ha continuat lo present acte ett. cuare ett. Testes ett. Salvator Joan et Andreas Bestard. ${ }^{28}$

Els jurats proposaren destinar part dels doblers de la Fortificació a construir una nova arca per substituir l'anterior malmenada. També a renovar els sacs on es dipositaven els noms dels candidats elegibles, a fer un cobri bufet i a instal-lar el moble en una estança endreçada a propòsit. Tot plegat reflecteix la realització d'un conjunt suficientment representatiu i acord amb la imatge renovada que perseguia la Universitat. Unes pàgines després es detalla el contracte que es féu per a la fabricació de la peça i que restà enregistrat en la junta celebrada el vint i tres de gener del mateix any:

Die XXIII mensis mensis januarii anno a nativitate domini MDCLXVIIII.

Sobre fer una caxa ab quatre panys.

Convocats, congregats y ajuntats su señoria dels illustres y molt magnífichs señors don Antoni Dameto y sos socios jurats ett. han acordat ab mestre Joan Oms sculptor fer y traballar en la sala del Consell una caxa de noguer ab quatre panys, ab sos escuts de lleutó brodats y claus deurades y empenonades, de llargària de vuit palms, ab sos peus y lletonets de noguer, ab dos pilars plans de pedra de Santany, ab deffinició y armes de la Universitat, obrat y deurat a ses costes, y posat en son lloch conforme les trasses se han fet. $Y$ per tota dita obre se ly promet donar doscentes lliures, salvo pedreñys y mans de picapadrers, y are de present se ly ha donat $100 \mathrm{~L}$ ab una pòliça en taula.

Y present dit Homs, promet fer dita obre a costes pròpries conforme las / las trasses dins dos mesos, salvo pedrenys y mans de picapadrer.

De tot lo qual para que const ad eternam rei memoriam se ha continuat lo present acte ett. cuare ett. Testes ett Johannes Llull et Andreas Bestard. ${ }^{29}$

Les pàgines posteriors no recullen com es dugué a terme la realització del moble. El Ilibre segueix fins les actes de maig de 1670 i no n'apareix més rastre. Amb tot, la concòrdia inclou dades fonamentals: I'existència prèvia d'una traça i les condicions estipulades com el termini de dos mesos, el noguer com la fusta a utilitzar del tot usual, les dimensions de vuit pams, la talla, el daurat i la ne- cessitat d'incloure el blasó de la Universitat i els quatre panys de llautó en forma d'escut. També el seu emplaçament al saló de sessions del Gran i General Consell. ${ }^{30}$

A més, a continuació dels "peus", -el cos inferior de la peça-, el contracte especifica uns "lletonets" (infants de mamella), que deuen correspondre a les figures angèliques. Així mateix fa referència a dos pilars de pedra de Santanyí fets per un picapedrer. Segons creiem suportaren la caixa al cos inferior. Possiblement ho feren en la zona posterior i després de perdre's en cert moment degueren ser substituïts per l'estructura de fusta actual.

Amb tot, la dada fonamental és que el contracte resol definitivament l'autoria i cronologia de la peça. L'autor es pot identificar com a Joan Oms Bestard (1639-1681). Fou un dels fills de Joan Antoni Oms Tomàs, responsable del primer cos de la façana de Cort (1650) i escultor principal d'una de les nissagues artístiques més extenses de Mallorca, que havia mort el 1667.

Les primeres notícies sobre el perfil biogràfic del citat mestre Joan es troben en estudis que citen la família dels Oms o que la relacionen amb obres específiques. ${ }^{31}$ Es sap que el pare nomenà hereu del seu taller artístic al primogènit, Gaspar Oms Bestard, mentre Joan figura com a marmessor, rebent una petita quantitat monetària. ${ }^{32}$ Marià Carbonell al-ludí sobre el seu rastre, menys perceptible:

Per la seva banda, Joan Oms Bestard, es casà força més jove, com hem vist, amb Joana Arbona Amengual. Com el seu germà, residia a la parròquia de Sant Miquel, però a l'illeta del forn que hi havia davant del convent de l'Olivar, no lluny del de Santa Caterina de Sena. Quan va morir el vint-i-u d'agost de 1681, precoçment, deixà vuit fills. ${ }^{33}$

L'autor afegeix a la biografia una acusació d'assassinat al col-lega Jeroni Pinya el 1661, que finalment acabà sense conseqüències en la seva vida professional. $^{34}$

A tot això s'han de sumar les dades que posteriorment han relacionat el dit Oms amb la resta de membres de la nissaga familiar ${ }^{35}$ i la documenta-

\footnotetext{
28 ARM, AH EU 78, Extraordinaris Universitat 1667-1670, fols. 108v-109r.

29 ARM, AH EU 78, Extraordinaris Universitat 1667-1670, fols. 110v-111r.

30 MUNTANER BUJOSA, Juan, 1968, p. 9-15.

31 SEBASTIÁN LÓPEZ, Santiago; ALONSO FERNÁNDEZ, Antonio, 1973, p. 90.

${ }^{32}$ Cal assenyalar la problemàtica existent envers el nom de Joan, a vegades citat com a Joan Antoni. RABASSA OLIVER, Gabriel, 1994, p. 71

33 CARBONELL I BUADES, Marià, 2007, p. 105. Vegeu també les p. 93, 104.

${ }^{34}$ CARBONELL I BUADES, Marià, 2007, p. 97. Vegeu també CARBONELL I BUADES, Marià, 2002, p. 100.
} 
ció que l'ha mostrat com a mestre, com a testimoni en encartaments d'artistes o examinador del Col-legi de Pintors i Escultors. ${ }^{36}$

El que més ens interessa ara és la formació de Joan Oms. Carbonell exposa com es desenvolupà junt al seu germà Gaspar al taller familiar del pare, Joan Antoni Oms. ${ }^{37}$ De fet els dos fills treballaren de ben jovenets al retaule del Roser de l'església de Sant Domingo de Pollença (1651-1662). Malgrat finalment I'hereu del taller fos el primogènit, Joan treballà en algunes obres importants del pare poc després de la seva mort. Ho féu al retaule major del convent dominic de Ciutat, que no es conserva (1644-1682). Es sap que per a dita obra féu un Sant Francesc i un Sant Pere, obrant i daurant a més les seves pasteres entorn de $1670 .{ }^{38}$ També treballà al convent de Sant Vicenç Ferrer de Manacor dels dominics (1665-S. XVIII), on féu dues fornícules el $1670 .{ }^{39}$

Uns anys més tard Joan Oms tallà una clau de volta de l'església de Sant Jeroni (1676), ${ }^{40}$ el retaule desaparegut del Sant Crist del convent de Santa Catalina de Sena i el de Santa Gertrudis de la parròquia de Santa Creu. ${ }^{41}$ Al catàleg d'obres cal afegir encara la fornícula que servia de reliquiari a la desapareguda capella dels Pardos de la Cartoixa de Valldemossa (1676). ${ }^{42}$ Per aquesta obra l'escultor féu un albarà als monjos que conserva la seva signatura.

Els darrers anys de vida Joan Oms féu la que fins avui es considerava la seva obra més significativa: el sagrari expositor del retaule major del convent de la Concepció de Palma (1676-1681), on encara repetia elements característics del taller patern com els àngels-estípit, ${ }^{43}$ els particulars caps de querubins o els poms de fruites penjats de garlandes.

A tot això avui afegim l'arca de les insaculacions de la Universitat. El preu estipulat en dues-centes lliures pel treball de la fusta reflecteix suficientment la seva importància. Cal comparar aquesta

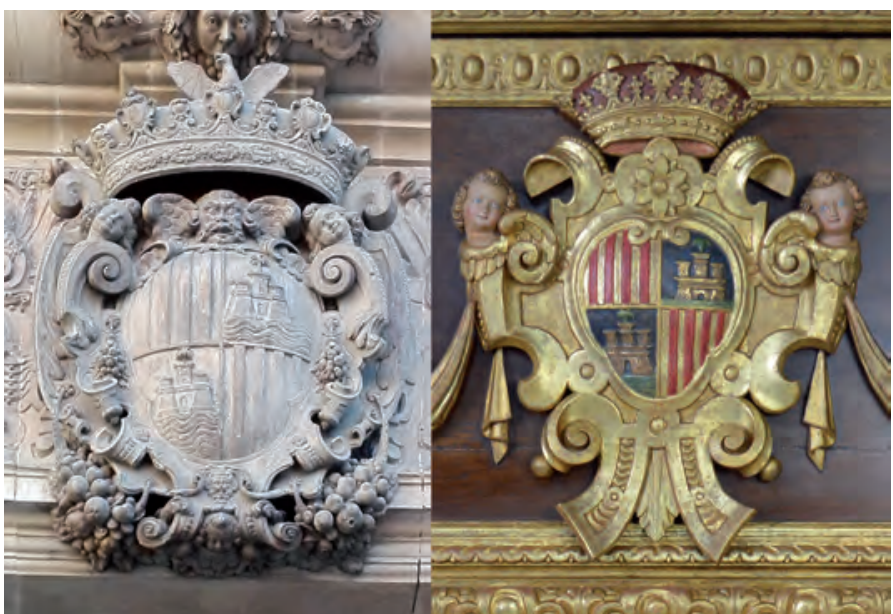

Fig. 3. Escut de la façana de Cort i de l'arca.

quantitat amb les cent setanta-cinc lliures acordades pel mateix Oms el 1681 per fer el retaule desaparegut del Santcrist del convent de monges dominiques, o les tres-centes cinquanta que costà el retaule de Santa Gertrudis de la parròquia de Santa $\mathrm{Creu}^{44}$ Sens dubte, ambdós tenien unes dimensions molt superiors.

Concloent, la formació de l'escultor al taller familiar i la continuació dels retaules iniciats pel pare durant els anys de la fabricació del moble de Cort poden explicar fins a quin punt Joan Oms reflectí sobre l'arca el llenguatge formal desplegat per Joan Antoni Oms.

\section{El ressò de l'obra arquitectònica i el context escultòric de l'edifici de Cort}

Al nostre parer la major originalitat que presenta l'arca de les insaculacions radica en concretar la particular visió escultòrica de Joan Oms sobre una tipologia coneguda de mobiliari. En definitiva es tracta d'una versió única d'arquimesa, un moble

35 FIOL PONS, Guillem, 2010, p. 134, 146, 151, 159, 163, 186, 277, 279, 292, 293, 294.

36 GAMBÚS SAIZ, Mercè; BARCELÓ ADROVER, Pep, 2014, p. 66, 257, 259, 263, 267, $268,277$.

37 CARBONELL I BUADES, Marià, 2002, p. 100.

38 RABASSA OLIVER, Gabriel, 1994, p. 76.

39 ROMAN, Rosa Júlia, 1996, p. 267-269.

40 ROMAN, Rosa Júlia, 1996, p. 267-269.

41 CARBONELL I BUADES, Marià, 2007, p. 97-98.

42 ARM, C-1255, Llibre d'albarans 1674-1722, fol. 6r, any 1676. Transcrit i comentat a BAUÇÀ DE MIRABÒ, Concepció, 2008, p. 302.

43 El documentà CARMONA MORENO, Félix, 2001, p. 128. Sobre la seva importància vegeu CARBONELL I BUADES, Marià, 2002, p. 100

${ }^{44}$ CARBONELL I BUADES, Marià, 2007, p. 97-98. 


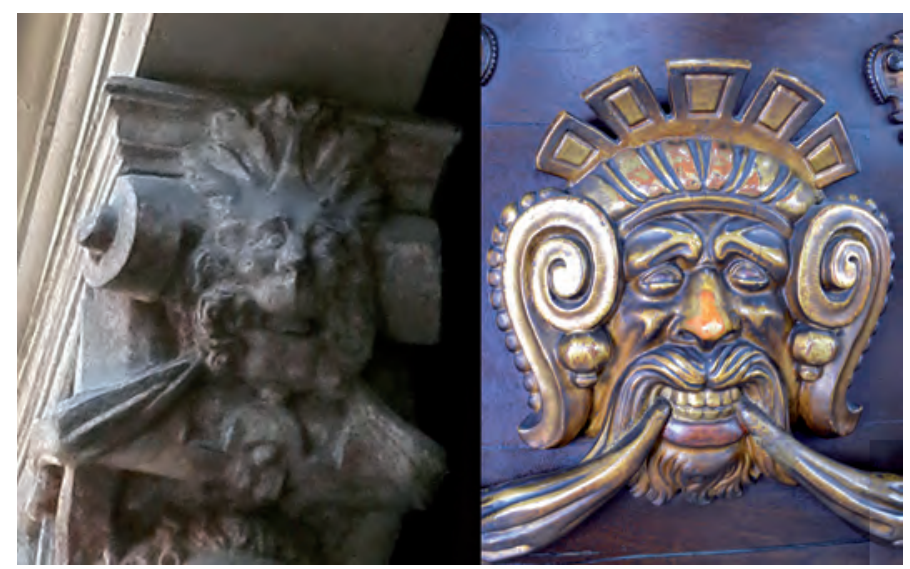

Fig. 4. Màscara de la façana Cort i de l'arca.

que es difongué a Mallorca a partir del segle XVI important-se primer de Catalunya i essent fabricat llavors pels artesans locals. ${ }^{45}$ No obstant, l'exemplar de Cort degué ser totalment distint dels models habituals, utilitzant un llenguatge culte classicista que l'acosta més a les talles dels cassoni i a les taules de les arquilles italianes. ${ }^{46}$

El protagonisme de l'alt relleu i dels motius antropomorfs -poc freqüent als mobles mallorquinsrespon a la visió de l'escultor. I com ja assenyalà la historiografia, l'entorn més proper d'inspiració iconogràfica per a Joan Oms a I'hora de fer l'arca fou el frontispici de Cort. Concretament el primer cos treballat per son pare el 1650. Malgrat els quasi vint anys transcorreguts entre els dos dissenys, ambdues obres utilitzen elements procedents dels repertoris manieristes vigents a l'illa. Un anàlisi comparatiu entre la façana i el moble mostra -més enllà de les diferències derivades de cada suport i tècnica-, la major qualitat del treball patern que s'evidencia en la riquesa d'elements $\mathrm{i}$ en un resultat més harmoniós.
Les semblances resulten significatives. A tall d'exemple cal comparar els blasons de Cort amb el de la caixa (Fig. 3). Hi coincideixen el perfil cordiforme, els àngels-estípits característics dels Oms, que presenten fesomies i pentinats semblants rematats amb motius auriculars, els cartrons retallats amb decoracions d'escates o la corona superior amb formes arrodonides, aplicacions i remats similars.

Igualment resulten comparables les màscares monstruoses ubicades a les mènsules de la tribuna de Cort i al frontal de la caixa (Fig. 4). Sostenen amb la boca drapejats i malgrat es tracta d'un model estès tallat amb variants, conserven la mateixa estructura general.

També es repeteixen recursos típics del taller familiar com els poms de fruites simètrics penjant de garlandes o els motius auriculars amb perfils similars (Fig. 5). Entre tots els motius destaquen els àngels-atlants. Marià Carbonell relacionà aquesta tipologia com a característica dels Oms i especificà que fou difosa per Gaspar Oms en l'àmbit del retaule. ${ }^{47}$ Més endavant Andreu Josep Villalonga cità les dues figures de l'arca com a àngels tinents i sostingué que podien ser els antecedents directes $d^{\prime}$ 'aquells àngels atlàntics. ${ }^{48}$ Avui exemplars com els del retaule de les ànimes de Purgatori de la parròquia d'Alaró (Joan Antoni Oms i Gaspar Oms, 1660-1667) ${ }^{49}$ indiquen que la tipologia dels àngelsatlants ja es fabricava al taller dels Oms poc abans de la confecció de l'arca.

D’altra banda cal contextualitzar la peça en l'entorn gremial de l'època. Segons la documentació l'arca i la sala del Consell es plantejaren com una primera fita de la decoració interior de l'edifici, engegada un pic acabades les obres essencials. La primera constituí un d'aquells encàrrecs en els que confluïen els interessos dels fusters i els escultors.

Com l'element moble que era, en principi la peça s'hauria d'haver encarregat a un fuster "primater", o sigui a aquell que realitzava obra fina de fusta i mobiliari. La seva feina es considerava me-

\footnotetext{
45 "Arquimesa: Mueble compuesto de una mesa y un arca sobre ella". A: FATÁs CABEZA, Guillermo; BORRÁS GUALIS, Gonzalo M., 1991, p. 30. A la Cartoixa de Valldemossa entre 1600 i 1602 els monjos en comanaren dues. És interessant comparar el preu d'aquells mobles amb les dos-centes lliures que costà l'arca de Cort. "Més per un scriptori o archimesa per la conreria, de fer 7 liures y per la ferramenta $3 \mathrm{~L}$, $18 \mathrm{~s}$; Més per una archimesa de Barcelona $3 \mathrm{~L}$, $12 \mathrm{~s}$ de port. Més per la sobra de dita archimesa, que costà 27 L, 16 s, 9 d". Arxiu de la Cartoixa de Montealegre, ACM, Resum dels gastos 1591-1780, fol. 12r.

${ }^{46} \mathrm{Com}$ a exemples vegeu el cassone decorat amb motius manieristes que correspon a la fitxa de catàleg 0000459 del Museo de Prado, MUSEO DEL PRADO, "Arca" (en línia), A: https://www.museodelprado.es/coleccion/obra-de-arte/arca/058cc869-314444f2-bfd8-ffd1ab22ed85 (10/04/2020).

47 CARBONELL I BUADES, Marià, 1996, vol 4, p. 318-320; 2002, p. 31, 98, 111.

48 VILLALONGA VIDAL, Andreu Josep, 2006, p. 518.

49 CARBONELL I BUADES, Marià, 2002, p. 98.
} 
cànica i no liberal com la dels escultors, però la competència entre els dos grups per monopolitzar el mercat provocava nombrosos problemes. ${ }^{50}$

Els darrers havien aprofitat la seva preeminència social, adquirida durant el segle XVII, per a imposar-se en treballs tradicionalment pertanyents als primers com caixes, arquilles i escriptoris. ${ }^{51}$ En aquests tipus de mobles la talla havia anat assolint una importància creixent que els escultors anaren copant. La inclusió de relleus treballats amb figures antropomorfes està documentada a partir del Renaixement en peces luxoses que primer s'importaren directament des d'Itàlia i que més tard es fabricaren a Mallorca seguint els nous gusts. ${ }^{52}$

A l'illa el conflicte entre els membres dels dos gremis havia acabat -aparentment- amb la concòrdia a la qual havien arribat el 1661, després d'un llarg plet. Els escultors s'havien assegurat com a pròpies les tasques de daurat i policromat així com la talla de sants de bulto, és a dir escultures, retaules, passos... en definitiva obra religiosa. ${ }^{53}$ Però en la pràctica acabaren dominant també els mobles de luxe i en concret la fabricació d'arquilles amb talla escultòrica, tal i com ja explicà Carbonell a partir de documentació datada el 1669 i per tant coetània.54

L'arca de les insaculacions fou feta, efectivament, per un escultor. La seva inspiració arquitectònica -àngels-atlants sostenint la caixa mitjançant una espècie d'entaulament motllurat, estípits, mascarons...-, el seu tractament inusualment volumètric, la profusió de daurats i la policromia demostren fins a quin punt excedí el tractament tradicional d'una peça de mobiliari. La seva concepció respon des del principi al treball d'un escultor i cal afegir, d'un mestre especialitzat en l'àmbit del retaule.

Finalment l'obra s'ha de posar en relació a l'ambient que l'embolcallà. Al mateix temps que es fabricava s'inicià l'enteixinat de l'estança on es reunien els jurats, citada als documents com la "sala inferior" de la Universitat. Constituí una coberta important, inserida en la tradició de teginats amb cassetons inaugurats a l'illa al Renaixement. ${ }^{55} \mathrm{En}$ cara que aquell sostre es va perdre en l'incendi de 1894, la seva construcció està documentada.

El 14 de juny de 1669 s'adquiriren les jàsseres, els vuit capitells que havien de rematar-les i els revoltons que havien de servir en la coberta de fusta. El més interessant però és que aquella compra es féu a Jeroni Oms, ${ }^{56}$ un altre membre fins avui desconegut de la nissaga, que necessàriament connecta amb l'autor de l'arca. Llavors es comanaren al fuster Thomàs Juan vuit plafons de cassetons, seguint el model d'un que ja es trobava instal.lat. ${ }^{57} \mathrm{El}$ contracte evidencia que el dissenyador de l'enteixinat no fou el fuster, a qui es pagà per concretar-lo. Probablement fou el citat Jeroni, però els do-cuments no ho detallen. El setembre 1670 es contractà a un altre escultor anomenant Tomàs Seguí per acabar el fris perimetral amb fullatges que havia de rematar l'enteixinat. ${ }^{58}$ Tot plegat reitera el poder dels escultors.

Aquell sòtil fou dibuixat abans de desaparèixer pel mestre d'obres Bartomeu Ferrà, que el destacà entre tots els fabricats a l'illa durant l'Edat Moderna. ${ }^{59}$ Es tracta del típic cassetonat d'un teginat culte renaixentista. Tanmateix, la importància que

\footnotetext{
50 En l'àmbit proper cal recordar els documentats a Barcelona al voltant de 1680. Vegeu al respecte BASSEGODA I HUGAS, Bonaventura, 1994, p. 50-52.

51 BERNAT ROCA, Margalida, 2009, p. 33.

52 Sobre això vegeu MASSOT RAMIS D'AIREFLOR, María José, 1995, p. 74; BERNAT ROCA, Margalida, 2009, p. 21. Vegeu exemplars concrets a FERRÀ PERELLÓ, Bartolomé; VIRENQUE, Julio, 1873, vol. 1, lám. X; BASSEGODA I HUGAS, Bonaventura, 2017, vol 2. lám. XI.

53 CARBONELL I BUADES, Marià, 2002, p. 31.

54 CARBONELL I BUADES, Marià, 2002, p. 32-33.

55 BAUÇÀ DE MIRABÒ, Concepció, 2017, p. 66-67.

56 "Acte de compre de capitells y jàceres a favor de Hieronim Homs Die XIIII mensis junyii anno a nativitate domini MDCLXVIIII. Convocats, congregats y apuntats su señoria dels illustres y molt magnífichs señors Nicolau de Sala donsell y sos socios jurats de la Universitat, de la casa de la Juraria de dita Universitat, lloch solit y acustumat ahont los negocis de aquella se acustumen tractar diffinir y terminar, per bé y utilitat de dita Universitat juntament ab lo magnífich Gerònim Doms ab qui se ha consertat compralli vuyt capitells per las jàsseras, a raó cent reals castallans cade capitell y cent vint y sinch revoltons que ha entregat, posats demunt el moll a rahó vint y quatre reals cade revoltó, los quals li prometen / prometen pagar de las mil lliuras que la Universitat se reserve del diner ab que contribueix a la Fortificatió per las obras de la Casa de la Universitat per sammanas o mesadas ab la forma que li apparexerà. De tot lo qual para que conste ett cuans [?]. Testes ett Joannes Llull et Andreas Bestard". ARM, AH EU 78, Extraordinaris Universitat 1667, fols. 136v-137r.

57 ARM, AH EU 79, Extraordinaris Universitat 1670-1673, fols. 9v-10r. Transcrit a GAMBÚS SAIZ, Mercè, 1998 , p. 101.

58 ARM, AH EU 79, Extraordinaris Universitat 1670-1673, fols. 42v-43r.

59 FERRÁ PERELLÓ, Bartolomé, 1899, p. 63.
} 


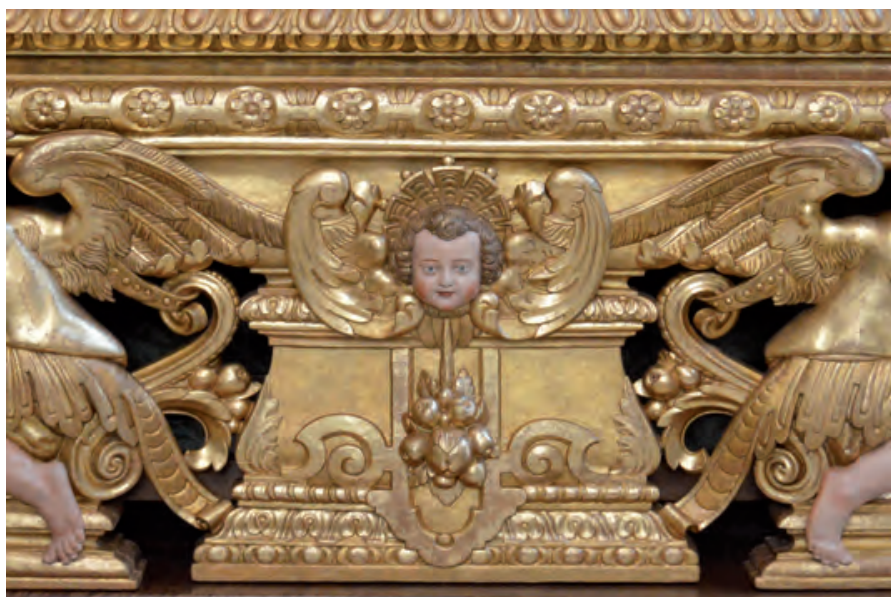

Fig. 5. Elements propis dels Oms en la peanya del cos inferior.

assoleixen els elements tallats en forma de fullatges i penjants, i les mènsules laterals evidencien la seva evolució siscentista. Aquelles vuit peces que corresponen als "capitells" adquirits a Jeroni Oms, foren dibuixades per Ferrà en forma de caps de querubins amb ales sobre decoracions auriculars 0 en forma de màscares sobre motllures vegetals (Fig. 5). Repeteixen tant la iconografia com els motius decoratius de l'arca que aixoplugaren. En definitiva, el 1669 els jurats aconseguiren complir la seva intenció de posar l'arca "en major forma, en part y aposento particular". .0

A més, Ferrà cita altres dos enteixinats ubicats al tram central de la tribuna inferior i a la peça superposada, coneguda com el "consistori petit". ${ }^{61}$ Els dos s'han perdut i no es conserva cap imatge. Pensam que segurament es construïren també en aquella època, i malgrat no coneguem documentació que ho certifiqui, demostrarien la continuïtat dels teginats siscentistes com a recurs decoratiu principal de la reforma de Cort.
Durant els mateixos anys es dissenyà també l'impressionant ràfec de fusta de la façana. Es sap que fou iniciat posteriorment a 1667, quan s'acabà l'obra de pedra del frontispici. L'estudi recent d'aquest obra per part d'Elvira González ha revelat novetats, com que el 1673 es trobava bastant avançada, perquè fou quan s'instal.laren els plafons del fris. ${ }^{62}$ Set anys després una coneguda visura evidenciava que el voladís era conclòs.

La concepció d'un ràfec tan treballat reflecteix novament la feina d'un escultor: Gabriel Torres Cladera, que passà a la posteritat gràcies a aquell i que també obrà alguns retaules. Vivia front a l'església de Sant Miquel, així que era veïnat de Joan Oms. L'amistat amb aquella família es remunta als pares d'ambdós. ${ }^{63}$ Dit nexe és rellevant en l'estudi que ens ocupa, com també ho és la relació de Torres amb l'àmbit de les fortificacions mallorquines. ${ }^{64}$ Avui sabem gràcies a la documentació que el 1663 havia estat nomenat mestre artiIler de la Universitat. ${ }^{65}$ Aquesta circumstància fou la que degué possibilitar el seu treball a la volada. Es tracta per tant d'un escultor familiaritzat amb el llenguatge arquitectònic $\mathrm{i}$ alhora especialitzat en la talla de la fusta.

Partint del programa decoratiu manierista desplegat en pedra sobre la façana i afegint la tècnica escultòrica barroca, Torres tallà un impressionant voladís de quatre metres d'amplària, únic al seu gènere. Cal reconèixer que per distintes que resultin formalment les seves figures, els atlants, les màscares, els penjolls de fruites o els motius auriculars no deixen de repetir el discurs de l'arca de les insaculacions.

\section{Evolució històrica de la peça}

El règim de la insaculació finalitzà en promulgar-se el Decret de Nova Planta derivat de l'arribada dels Borbons. Quan s'implantà el 1717 comportant la suspensió de les antigues institucions privatives del Regne de Mallorca, ${ }^{66}$ I'arca deixà de complir la seva

\footnotetext{
${ }^{60}$ ARM, AH EU 78, Extraordinaris Universitat 1667-1670, fol. 108v.

${ }^{61}$ FERRÁ PERELLÓ, Bartolomé, 1899, p. 64.

62 GONZÁLEZ GOZALO, Elvira, en premsa.

63 Per la seva biografia vegeu FURIÓ, Antonio, 1839, p. 183-184 i CARBONELL I BUADES, Marià, 2002, p. 112-113.

${ }^{64}$ BAUÇÀ DE MIRABÒ, Concepció, en premsa.
}

65 "E aquex mateix dita su señoria confiats de la legalitat y sufficiència de Gabriel Torres esculptor li fan gratia y concessió de dita plaça de artiller donant llur beneplàcit ab lo salari emoluments y honres de dit ofici (...) lo qual Gabriel Torres esculptor present de grat accepta dita grazia y mercè, promet y jura de bé y lealment haverse en son offici pro quibus oblibona ett ex pacto perconam ett large ett". ARM, AH EU 76, Extraordinaris Universitat 1661-1664, fol. 103v.

${ }^{66} \mathrm{Amb}$ tot, el 28 de maig de 1716 ja s'havia suspès l'extracció anual dels jurats de Ciutat: "Jueves antes de Pentecostés en que debía tener lugar la extracción anual de los 6 jurados de la C. y R., se suspendió esta diligencia por mandato del marqués de Lede, así como el nombramiento de los demás oficiales de la Ciudad, prosiguiendo todos en sus destinos hasta nueva orden". CAMPANER Y FUERTES, Álvaro, 1881, p. 510. 
funció. Poc després es suprimiren definitivament les institucions pròpies i amb elles el nomenament dels jurats de la Universitat. ${ }^{67}$ La peça cessà d'emprar-se quotidianament.

Algunes fonts refereixen que el moble s'aprofità per custodiar al seu interior els fons de la Causa Pia Lul-liana, malgrat sembla que, en tot cas, es tractaria d'una confusió amb l'arca més petita de tres panys. ${ }^{68}$ Pensam que degué ser en aquell moment quan es degué retirar de la sala de sessions.

La progressiva inutilització de dependències al primer pis entorn a la meitat del segle XIX i la situació de ruïna que patí l'edifici des de la dècada dels setanta ${ }^{69}$ degueren suposar una nul.la conservació preventiva de la peça. El batlle de Palma el vuit d'agost de 1892 contestava a la Comissió de Monuments poc abans de començar la reforma de I'edifici:

En épocas lluviosas no hay medios de agotar los encharcamientos que se producen en los departamentos altos de la casa por efecto de la inmensidad de goteras imposibles de evitar. No hay departamentos útiles bastantes para las oficinas que el servicio de la Casa exige, y por consecuencia no puede atenderse á la conservación de muebles y efectos. ${ }^{70}$

L'incendi declarat a l'Ajuntament de Palma el 28 de febrer de 1894 ha aportat més notícies sobre l'evolució recent de l'arca de les insaculacions. Afectà a una tercera part de l'edifici, espacialment el vestíbul inferior i en menor mesura al primer pis, on devia estar aquella. ${ }^{71}$ El primer de març següent la premsa local publicava com havia patit desperfectes degut al foc: "Todos los cuadros de interés histórico se han salvado; otros están algo destrozados ó chamuscados, lo mismo que la antigua y artística arca". ${ }^{72}$ Pàgines més endavant es feia una "Relación de muebles y efectos deteriorados, susceptibles de reparación, á consecuencia del incendio del día 28 de febrero". Dins aquesta i al "Salón Ilamado pequeño" s'inventarià: "Un arca artística dorada es-

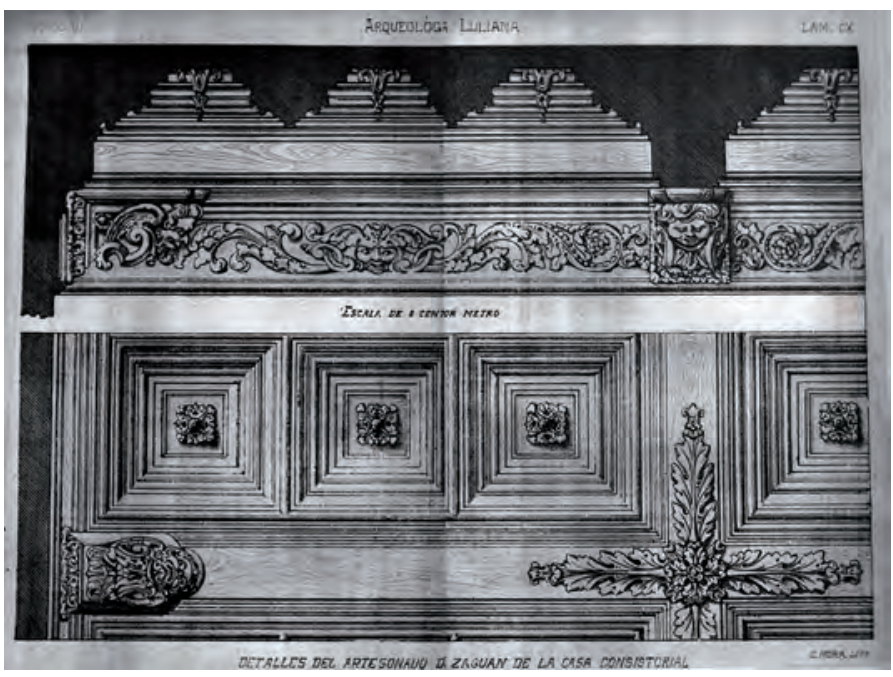

Fig. 6. Bartomeu Ferrà i Perelló, Techos artísticos en la isla de Mallorca, 1899, lám. CX.

tilo renacimiento, cinco retratos de medio cuerpo, un cortinaje de yute". Pitjor sort van córrer "Dos cuadros de medio cuerpo deteriorados y en estado inservible". ${ }^{73}$

El saló citat correspon segurament al citat per Juan Cortada com a saló d'hivern: "Tiene el ayuntamiento dos salas en que reunirse, una para el invierno que es chica y como un cuarto cualquiera, y otra para el verano que es grandiosa, no más que por el tamaño. En la primera hay un buen cuadro de Van Dyck [...]". ${ }^{74}$ Malgrat no l'esmenta, un pic retirat de la sala de sessions el moble es degué conservar al pis principal, raó per la qual no acabà patint danys irreversibles.

Poc després la Diputació Provincial promogué la restauració de les peces afectades i es va habilitar una sala del consistori, evitant trasllats perillosos

67 “Por Real decreto de 22 de julio de este año 1718 ordenó el monarca, que no hubiese G. y G. Consejo ni otro cuerpo que representara al Reino: que no se celebrase sorteo para ningún cargo: que los Jurados se llamaran regidores, limitándose sus atribuciones y facultades á lo económico y político de la poblacion y distrito de cada ciudad, villa ó lugar". CAMPANER Y FUERTES, Álvaro, 1881, p. 65. S'explica també a PIFERRER, Pablo.; QUADRADO, José María, 1968, p. $252-253$.

68 PONS I FÁBREGAS, Benito, 1895, p. 138; MUNTANER BUJOSA, Juan, 1968, p. 14; PÉREZ MARTíNEZ, Llorenç, 2004, p. 8-9.

69 CANTARELLAS CAMPS, Catalina, 1998, p. 119.

70 FERRÁ PERELLÓ, Bartolomé, 1892, p. 6.

71 En aquest primer pis hi havia "[...] antesala, sala de espera, pequeño Consistorio, despacho del Alcalde, Salón de sesiones, secretaría provisional, cinco despachos de negociados, una salita para conferencias de Sres. Concejales y una pieza de paso convertida provisionalmente en archivo de libros de la antigua tabla numularia". FERRÁ PERELLÓ, Bartolomé, 1892.

72 FERRÁ PERELLÓ, Bartolomé, 1895, p. 19.

73 FERRÁ PERELLÓ, Bartolomé, 1895, p. 35.

74 CORTADA I SALA, Joan, 2008, p. 57. 
per a la seva integritat. ${ }^{75}$ L'informe fet el 1895 per I'arxiver municipal de Cort constitueix la major font d'informació coneguda sobre la intervenció feta a l'arca:

\section{Caxa de beato Ramón}

Arcón dorado, con esculturas coloridas, estilo renacimiento, montado sobre un banco adornado siguiendo el mismo gusto.

Generalmente se llama á esta arca la caxa del Beato Ramón porque en ella se guardaban los libros de la Obra pía Luliana.

El fuego del año 1891 consumió la tapa y parte del pie, dañando el dorado y la pintura de la talla, pero ha sido concienzdamente restaurada por el escultor don Francisco Sacanells.

Las tablas laterales del pie, que faltaban de tiempo inmemorial, también han sido labradas por el mismo artífice bajo la dirección del infrascrito. ${ }^{76}$

Seguint aquesta descripció, cal destacar els importants danys patits per la tapa superior, els daurats $\mathrm{i}$ la policromia. A més s'indica la desaparició històrica de dos plafons laterals del suport, que foren tallats de nou per l'escultor Francesc Sacanell. Així per tant avui dia cal destriar en la peça la part original siscentista de l'obrada en època contemporània. Desconeixem més detalls de la restauració o les raons de l'elecció de Sacanell per a dur-la a terme. ${ }^{77}$ En tot cas sabem que la intervenció fou realitzada el $1895,{ }^{78}$ sense que n'apareix-hi constància a les actes municipals corresponents. ${ }^{79}$ Cal inserir-la en el marc $d^{\prime}$ 'una sèrie d'actuacions relacionades amb les obres de fusta com l'enteixinat vermell i el daurat del nou saló de sessions que s'aprovà el mateix any. ${ }^{80}$

Finalment, es sap que la caixa fou restaurada novament als anys seixanta del segle $\mathrm{XX}$, però pel moment no hem localitzat la documentació sobre dita actuació.

\section{Conclusió}

L'arca de les insaculacions de Cort forma part d'un conjunt d'obres que en la segona meitat del segle transformaren la Casa de la Universitat de la mà dels Oms. La reforma que havia de dotar dita institució d'una aparença renovada començà al cos inferior de la façana, amb un programa decoratiu en pedra d'origen manierista en transició cap el barroc. El discurs iniciat per Joan Antoni Oms el 1650 continuà amb un altre escultor Antoni Carbonell entre 1666 i 1667 a les plantes noble i superior. Acabada l'obra de pedra, els treballs continuaren amb el plantejament de la decoració interior basada en un seguit de treballs en fusta que, repetint la influència classicista, foren dirigits per coneguts escultors barrocs.

La primera documentada és justament l'arca, obrada el 1669 per un dels fills del citat Joan Antoni. L'ocasió de fabricar una peça tan representativa i nuclear, a to amb l'edifici que la custodiava degué ser la causa fonamental que impulsà a Joan Oms a assumir el vocabulari manierista. Mitjançant aquest, treballà un tipus de moble conegut d'una forma absolutament inèdita a Mallorca.

Recollí l'herència del pare en la façana i convertí l'arca en una vertadera escultura que s'allunyava de tota la tradició artesanal propera. El protagonisme que atorgà a tota la talla respon clarament al seu ofici d'escultor. Però a més, recollí i plasmà els motius típics del taller familiar.

Els infantons que indicava inicialment el contracte es transformaren en dos fornits àngels-atlants, capaços de "suportar" el pes de la caixa superior. Troben els paral.lels més directes en aquells atribuïts fins avui al germà -Gaspar-, en l'àmbit del retaule, però es diferencien pel vestuari de referències romanes que escurça les túniques i les mànigues per deixar l'anatomia a la vista. El discurs manierista dels Oms s'estén per tota la peça, gràcies als relleus en forma d'àngels-estípits, a les màscares monstruoses i a les garlandes que envolten l'escut de la Universitat. Amb tot el sentit volumètric de l'obra, junt a certa expressivitat continguda denoten l'escultor barroc.

Un cop finalitzada, l'arca pogué inspirar l'enteixinat que aixoplugant-la cobrí el saló de juntes mesos

\footnotetext{
75 PUJALS I MAS, Margalida, 1999, p. 107-114.

76 La descripció s'inclou a l'apartat dedicat al "Mobiliario artístico", amb el n² 20. PONS I FÁBREGAS, Benito, 1895, p. 138.

77 Únicament es sap al respecte que l'escultor havia signat un document en defensa de la tribuna de la façana de Cort el 5 de setembre de 1892 titulat "Exposición dirigida por los vecinos de esta ciudad al excelentísimo Ayuntamiento, con motivo de las obras emprendidas en el Consistorio". FERRÁ PERELLÓ, Bartolomé, 1892, p. 19.

78 "Este arcón fué dañado por el fuego en el incendio ocurrido en la Casa Consistorial durante la noche del 28 de febrero de 1894 [...]. El año siguiente fué concienzudamente restaurado por el escultor D. Francisco Sacanell en la forma que se conserva hoy día". MUNTANER BUJOSA, Juan, 1968, p. 15

79 La restauració no es recull tampoc a: FERNÁNDEZ LABANDERA, José (Ayuntamiento de Palma). Notas de Acuerdos Municipales desde 1851 á 1907. Palma: J. Tous, 1908, pp. 147-155. Únicament es sap que el juny de 1897 l'Ajuntament de Palma decidí formar un inventari de tots els seus mobles $\mathrm{i}$ estris.

80 FERRÁ PERELLÓ, Bartolomé, 1895, p. 199.
} 
després. Així ho suggereixen els àngels i les màscares que s'adquiriren a un altre artista proper: Jeroni Oms. Aquest continuà la tradició dels teginats mallorquins, demostrant alhora fins a quin punt els escultors n'havien assolit el control i establint una línia de continuïtat en tota l'obra de Cort a l'entorn de dita nissaga. Probablement aquella arribà també a altres cobertes de l'edifici, avui desaparegudes.

Finalment el discurs de la fusta culminà en la façana, gràcies a l'espectacular volada de l'escultor Gabriel Torres -també lligat a Oms-, construïda entre la dècada dels setanta i 1680 . En ella els motius manieristes continuaren l'argumentari de la pedra i de l'arca, complementant els atlants amb cariàtides i desplegant la poderosa volumetria i rotunditat del barroc.

\section{Bibliografia}

AGUILÓ, María Paz. El mueble en España de los siglos XVI y XVII, Madrid: Antiquaria, 1993.

BASSEGODA I HUGAS, Bonaventura. "Notes a l'entorn del moble a Catalunya als seges XVI i XVII. A: El moble català, Barcelona: Electa, 1994, p. 44-61.

BASSEGODA I HUGAS, Bonaventura. Bartomeu Ferrà, Álbum artístico de Mallorca. Bellaterra: UAB, 2017. (en línia). A: <https://ddd.uab.cat/record/73684> (data de consulta: 06-04-2020).

BAUÇÀ DE MIRABÒ, Concepció. La Real Cartuja de Jesús de Nazaret de Valldemossa. Formación y evolución de su patrimonio histórico-artístico. Palma de Mallorca: J. J. de Olañeta-UIB, 2008.

BAUÇÀ DE MIRABÒ, Concepció. "La casa de I'Almoina i la Catedral de Mallorca. Un diàleg entre el Gòtic i el Renaixement", BSAL, 2017, vol. 73, n 871, p. 61-69.

BAUÇÀ DE MIRABÒ, Concepció. "La culminació escultòrica d'un voladís de fusta". A: GONZÁLEZ GOZALO, E. (coor.). El voladís de Cort. Palma de Mallorca: Ajuntament de Palma, en premsa.

BERNAT ROCA, Margalida. "Algunes notes històriques sobre l'ofici de fusters (Mallorca, segles XIII-XVII)". A: COLL, K. (coor.). El moble a Mallorca: segles XIII-XX: estat de la qüestió. Palma: Consell de Mallorca, 2009, p. $15-49$

CAMPANER Y FUERTES, Álvaro. Cronicón mayoricense, Noticias y relaciones históricas de Mallorca. Palma de Mallorca: Establecimiento tipográfico de Juan Colomar y Salas editor, 1881.

CANTARELLAS CAMPS, Catalina (coor.). Ajuntament de Palma. Historia, arquitectura y ciudad, Palma de Mallorca: Ajuntament de Palma, 1998.

CANTARELLAS CAMPS, Catalina. "Las transformacions contemporáneas". A: CANTARELLAS CAMPS, C. (coor.). Ajuntament de Palma, Historia, arquitectura i ciudad. Palma: Ajuntament de Palma, 1998, p. 111-139.

CARBONELL I BUADES, Marià. "Torres, Els". A: FRONTERA, G. (dir.). Gran Enciclopèdia de la pintura i l'escultura a les Balears, 4 vols. Palma de Mallorca: Promomallorca, 1996, vol. 4, p. 318-320.

CARBONELL I BUADES, Marià. Art de cisell i de relleu. Palma: J. J. de Olañeta, 2002.

CARBONELL I BUADES, Marià. "Els escultors barrocs de la família Oms: precisions biogràfiques i noves contribucions al catàleg". BSAL, 2007, vol. 63, n 861, p. 93120.
CARMONA MORENO, Félix. "Iconografía de la iglesia y monasterio de Nuestra Señora de la Concepción de las Agustinas en Palma de Mallorca". BSAL, 2001, vol. $57, n^{\circ} 855$, p. 125-152.

COLL, Kika. "Barroc. Segles XVII-XVIII". A: COLL, Kika. (coor.) El moble a Mallorca. Segles XIII-XX. Estat de la qüestió. Consell de Mallorca: Palma de Mallorca, 2009, p. 137-145.

CORTADA I SALA, Joan. Viaje a la Isla de Mallorca en el estío de 1845. Miquel Font Editor: Palma, 2008.

FATÁS CABEZA, Guillermo; BORRÁS GUALIS, Gonzalo M. Diccionario de términos de arte y elementos de arqueología, heráldica y numismatica, Madrid: Alianza Editorial, 1991

FERNÁNDEZ LABANDERA, José (AYUNTAMIENTO DE PALMA). Notas de Acuerdos Municipales desde 1851 á 1907. Palma: J. Tous, 1908.

FERRÁ PERELLÓ, Bartolomé. "Caxes y Arquilles". La Ignorància, núm. 74, Palma, 1970 (1 $1^{\mathrm{a}}$ ed. 1880), p. 1-2.

FERRÁ PERELLÓ, Bartolomé. Reconstrucción de la Casa Consistorial de Palma. Apuntes. Palma de Mallorca: Imprenta de Felipe Guasp, 1892.

FERRÁ PERELLÓ, Bartolomé. Transformaciones de la Casa Consistorial de Palma (Artículos publicados por la prensa periódica relativos al proyecto aprobado en 4 de marzo de 1892). Palma: Tipografía Católica Balear, 1895.

FERRÁ PERELLÓ, Bartolomé. "Techos artísticos en la isla de Mallorca (apuntes de mi cartera)". BSAL, 1899, vol. 3, n' 229, p. 62-64.

FERRÁ PERELLÓ, Bartolomé; VIRENQUE, Julio. Álbum artístico de Mallorca, Palma: Imprenta de Pedro José Gelabert, 1873

FIOL PONS, Guillem. El taller de l'artista a Mallorca els segles XVI-XVIII. La nissaga dels Oms (Formació, materials, tècniques, procediments $i$ fonts). Memòria d'investigació, Palma de Mallorca: Universitat de les Illes Balears, 2010. A: <http://ibdigital.uib.cat/greenstone/collect/memoriesUIB/index/assoc/Fiol Pon.dir/Fio Pons_Guillem.pdf> (data de consulta: 06-04-2020).

FURIÓ, Antoni. Diccionario de los ilustres profesores de Bellas Artes en Mallorca. Palma: Gelabert y Villalonga, 1839.

FURIÓ, Antoni. Panorama de las Islas Baleares. Palma de Mallorca: Panorama Balear, 1966.

GAMBÚS SAIZ, Mercè. "La problemática del manierismo en el arte mallorquín: un modelo periférico". Príncipe de Viana, 1991, n 12, Anejo, p. 197-202.

GAMBÚS SAIZ, Mercè. "La configuración arquitectónica del edificio". A: CANTARELLAS, C. (coor.). Ajuntament de Palma. Historia, arquitectura y ciudad. Palma de Mallorca: Ajuntament de Palma, 1998, p. 89-109.

GAMBÚS SAIZ, Mercè; BARCELÓ ADROVER, Pep. Les arts a Mallorca entre els Àustries i els Borbons, Palma de Mallorca: Lleonard Muntaner editor, 2014.

GARCÍA RUIPÉREZ, Mariano; FERNÁNDEZ HIDALGO, María del Carmen. Los archivos municipales en España durante el Antiguo Régimen: Regulacions, conservació, organización y difusión, Cuenca: Ediciones de la Universidad de Castilla La Mancha, 1999.

GONZÁLEZ GOZALO, Elvira. "Una aproximació al monument". A: GONZÁLEZ GOZALO, E. (coor.). El voladís de Cort. Palma de Mallorca: Ajuntament de Palma, en premsa.

HABSBURGO LORENA, Archiduque Luis Salvador. Mallorca. Las Baleares descritas por la palabra y el dibujo (Die Balearen). Palma de Mallorca: J. J. de Olañeta, 2003.

LATORRE CIRIA, José Manuel; PÉREZ PÉREZ, Isabel. El gobierno de la ciudad de Teruel en el siglo XVII. Zaragoza: Prensas universitarias de Zaragoza, 2006. 
LLABRÉS MULET, Jaume. "Mallorca i Menorca, una reflexió sobre les Arts Decoratives a les Balears", Revista Estudi del moble, 2009, vol. 10, p. 12-19.

MADOZ, Pascual. Diccionario geográfico-histórico-estadístico de España y sus posesiones de ultramar. 16 vols. Madrid: Imprenta del Diccionario geográfico estadístico-histórico de Pascual Madoz, 1846-1850, vol. 13.

MASSOT RAMIS D'AIREFLOR, María José. El moble a les IIles Balears. Segles XIII-XIX. Palma de Mallorca: Institut Balear de Disseny, 1995.

MATHEU MULET, Pedro Antonio. Palma de Mallorca monumental. Palma de Mallorca: Editorial Plus Ultra, 1958.

MEDEL, Ramón. Manual del viajero en Palma de Mallorca. Palma de Mallorca: Imprenta Balear de Pedro José Umbert, 1849 .

MUNTANER BUJOSA, Juan. Bosquejos de la ciudad de Palma. Palma de Mallorca: Publicaciones del Ayuntamiento de Palma de Mallorca, 1968.

MUSEO DEL PRADO. "Arca" (en línia), A: https://www. museodelprado.es/coleccion/obra-de-arte/arca/058cc 869-3144-44f2-bfd8-ffd1ab22ed85 (10/04/2020).

PÉREZ MARTÍNEZ, LLORENÇ. Els fons manuscrits lul.lians de Mallorca: Fons lul.lians a biblioteques espanyoles. Barcelona: Universitat de Barcelona, 2004, p. 8-9.

PIFERRER, Pablo; PARCERISA, Francesc Xavier. Recuerdos y bellezas de España. Mallorca. Obra destinada a dar a conocer sus monumentos, antigüedades y vistas pintorescas en láminas dibujadas del natural y litografiadas por F.J. Parcerisa, acompañadas de texto por P. Piferrer. Barcelona: Imprenta de Joaquín Verdaguer, 1842.

PIFERRER, Pablo; QUADRADO, José María. Islas Baleares. Palma de Mallorca: Ediciones de ayer, 1968.

PONS I FÁBREGAS, Benito. Memoria presentada por el personal del archivo de la ciudad. Informe sobre restauración de cuadros. Dictámen de la comisión de gobierno exterior. Catálogos de los cuadros y objetos artísticos ó arqueológicos que se custodian en las casas consistoriales. Palma de Mallorca: Establecimiento tipográfico del comercio, 1895.

POU AMENGUAL, Miquel. "Sobre la retaulística de Binissalem durant l'època moderna". BSAL, 2014, vol. 70, $n^{\circ} 868$, p. $165-183$.
PUJALS I MAS, Margalida. "El fons artístic i documental de l'Ajuntament de Palma segons Benet Pons i Fàbregues". A: El món dels professionals i dels intel.lectuals: Benet Pons i Fàbregues (1853-1922). Palma: Fundació Emili Darder, 1999, p. 107-114.

RABASSA OLIVER, Gabriel. "Los Homs y el convento de Santo Domingo". Memòries de l'Acadèmia Mallorquina d'Estudis Genealògics, 1994, vol. 6, p. 69-77.

RODRÍGUEZ LÓPEZ, María del Carmen. "Del arca de los documentos y del arca de tres llaves. Su empleo en la península Ibérica y en Hispanoamérica". A: GARCíA NISTAL, J. (coor.). Imagen y documento. Materiales para escribir una historia cultural. León: Ediciones el Forastero, 2014, p. 189-204.

ROMÁN QUETGLAS, Rosa Júlia. "El retaule barroc de l'església conventual de Sant Vicenç Ferrer. Manacor". $B S A L, 1996$, vol. 52, $n^{\circ} 850$, p. 265-276.

SEBASTIÁN LÓPEZ, Santiago; ALONSO FERNÁNDEZ, Antonio. Arquitectura mallorquina moderna y contemporánea. Palma: Estudio General Luliano, 1973.

SEBASTIÁN LÓPEZ, Santiago. "Arte". A: Baleares, Madrid: Fundación Juan March, 1974, p. 141-315.

VARGAS PONCE, José. Descripciones de las islas Pithiusas y Baleares. Madrid: Imprenta de la viuda de Ibarra, 1787.

VERRIÉ, Fréderic Pau. Guías artísticas de España. Mallorca. Barcelona: Ed. Aries, 1948.

VIDAL, Josep Juan. "El poder municipal en la capital maIlorquina (s. XIII-XVIII)". A: CANTARELLAS, C. (coor.). Ajuntament de Palma. Historia, arquitectura y ciudad, Palma de Mallorca: Ajuntament de Palma, 1998, p. 9-29.

VILLALONGA VIDAL, Andreu Josep. "El retablo barroco de atlantes en Mallorca". A: HERNÁNDEZ SOCORRO, M. de los R. (dir.), XVI Congreso Nacional de Historia del Arte. La multiculturalidad en las artes y en la arquitectura, Las Palmas de Gran Canaria, del 20 al 24 de noviembre de 2006, 2 vols. Las Palmas de Gran Canaria: Gobierno de Canarias i Anroart Ediciones, 2006, vol. 1, p. 515-522.

XICARANDA. CONSERVACIÓ I RESTAURACIÓ DE BÉNS CULTURALS, SL. Informe de conservación-restauración del arca d'insaculacions de l'Ajuntament de Palma. Proyecto y presupuesto, Expediente 2019/18, 2019. 